Document downloaded from:

http://hdl.handle.net/10251/154023

This paper must be cited as:

Tarach, KA.; Góra-Marek, K.; Martínez-Triguero, J.; Melian-Cabrera, I. (2017). Acidity and accessibility studies of desilicated ZSM-5 zeolites in terms of their effectiveness as catalysts in acid-catalyzed cracking processes. Catalysis Science \& Technology. 7(4):858-873. https://doi.org/10.1039/c6cy02609e



The final publication is available at

https://doi.org/10.1039/c6cy02609e

Copyright The Royal Society of Chemistry

Additional Information 


\section{Acidity and accessibility studies of desilicated ZSM- 5 zeolites in terms of their effectiveness as catalysts in acid-catalyzed cracking processes}

Karolina A. Tarach ${ }^{a, *}$, Ignacio Melián-Cabrera ${ }^{b, c, *}$, Joaquin Martinez-Triguero ${ }^{d}$ and Kinga Góra-Marek ${ }^{a}$

a Faculty of Chemistry, Jagiellonian University in Kraków, 3 Ingardena St., 30-060 Kraków, Poland, phone: +4812663 2081, fax: +48126340515

${ }^{b}$ Chemical Engineering Department, ITM, Faculty of Mathematics and Natural Sciences, University of Groningen Nijenborgh 4, 9747 AG Groningen, The Netherlands

c European Bioenergy Research Institute (EBRI), School of Engineering and Applied Science, Aston University, Aston Triangle, Birmingham B4 7ET, United Kingdom

d Instituto de Tecnología Química, Universidad Politécnica de Valencia, Camino de Vera s.n., 46022 Valencia, Spain

Corresponding Authors:

* Karolina A. Tarach; P: +48(12)663 20 81; F: +48(12)634 05 15; E-mail address:

karolina.tarach@uj.edu.pl

* Ignacio Melián-Cabrera; P: +44(0)121 204 3046; E-mail address: i.melian-cabrera@aston.ac.uk 


\begin{abstract}
The structural, textural and acidic characteristics of hierarchical ZSM-5, obtained with different desilication approaches, and the effect of those parameters on the reactivity in various cracking reactions of variable feedstock size and severity have been investigated. Emphasis is given in understanding the sites accessibility; this was investigated by textural analysis, FTIR probe molecules (pivalonitrile and collidine) and reactions involving $n$-decane, 1,3,5-tri-isopropylbenzene (TIPB), and LDPE/HDPE. Higher surface areas and narrower pore size distribution were obtained for $\mathrm{NaOH} \& \mathrm{TBAOH}$-treated materials, as compared to the $\mathrm{NaOH}$-treated ones. FTIR studies of pivalonitrile and collidine adsorption correlate well with the mesopore surface area. For $n$-decane cracking activity, the acid strength is a determining factor. Contrarily, the TIPB cracking activity was improved by the developed mesoprosity of alkaline treated zeolites, and this was correlated to the pivalonitrile and collidine accessibility factors. The major reactivity differences for the cracking of LDPE/HDPE are found with the linear HPDE at low conversions; at higher conversions the differences vanish. The increased acid sites accessibility leads to an enhanced cracking activity, as determined by a decrease of the $T_{5 \%}$ and $T_{50 \%}$; both parameters are linearly dependent to the pivalonitrile and collidine accessibility factors, for LDPE and HDPE. The $T_{5 \%}$ for HDPE is more influenced by the accessibility factors than it is for LDPE. This is explained by the branching degree of HDPE and LDPE; therefore lineal HDPE is more sensitive by the enhanced amount of pore mouths of ZSM- 5 channels on the mesopores. At high conversion, the influence of the $T_{50 \%}$ with the accessibility factors for HDPE and LDPE is weaker, suggesting that the cracking at this stage involves intermediate molecules of smaller size with less diffusional limitations.
\end{abstract}

Keywords: catalytic cracking, TIPB, $n$-decane, LDPE, HDPE, zeolites, desilication, accessibility. 


\section{Introduction}

Hierarchical zeolites combining an intrinsic acidity of microporous zeolites without diffusional limitations, typical of mesoporous materials, have proven to be effective catalysts in numerous catalyzed reactions ${ }^{1-3}$. Several different approaches concerning the synthesis and modifications have been developed to prepare hierarchically porous zeolites. The synthesis methods are gathered around two main routes: bottom-up methods employing templates (e.g. surfactants, porous carbons, cationic polymers, etc. $)^{4-7}$ and top-down approaches concerning preferential extraction of silica or alumina from the zeolite structure ${ }^{8-11}$. The zeolites obtained in the presence of surfactants can be characterized by having a high concentration and strength of acid sites with uniform and usually homogeneous mesopores. On the other hand, a preferential zeolite demetalation is one of the most attractive postsynthesis modification methods in operational and costs terms. Demetalation processes not only generate the mesoporosity but also affect the acidity of hierarchical zeolite, modifying mainly the nature of the acidic sites ${ }^{9,12}$. Among the various post-synthesis methods, the desilication, i.e. selective silicon removal from zeolite framework, is being one of the most efficient and economic routes of mesoporosity generation. Desilicated zeolites of different types of structures and various $\mathrm{Si} / \mathrm{Al}$ ratios have been reported as active catalysts, with effectively generated intraparticle mesoporosity. Together with the alkaline treatment, the use of pore directing agents ${ }^{9,13,14}$ allowed for a more effective preservation of the crystallinity as well as a proper pores connectivity, followed by enhanced catalytic activity ${ }^{1-3}$. The so-modified zeolites demonstrated an increased sites' acidity and accessibility responsible for a more efficient reaction yield over the catalytically active centers. Higher activity has been especially well seen in the case of bulky and branched reactants, where diffusional constrains limit the reaction occurrence only to the zeolite grains' surface.

Desilicated zeolites possess features making them promising catalysts in plastic waste cracking reactions ${ }^{15,16}$. The recycling of plastic waste is an important environmental problem; production and post customer plastic wastes reach values of million tones, and the main disposal method is limited to landfilling ${ }^{17}$. The thermal pyrolysis of polymers requires high temperatures of restoring plastic waste to manufacturing lines in form of gaseous and liquid products, which can be further used as fine chemical feedstocks or fuel-like hydrocarbons. In this regard, the catalytic cracking of plastic waste can ensure lowering the temperature, higher selectivity to the desired products and a better yield of the process. Different acid porous materials have been considered as potential catalysts for the cracking of polyethylene such as silica-alumina, commercial zeolites and mesostructured materials ${ }^{17,18}$. The ZSM-5 zeolite possessing strong acid sites is a highly active and selective catalyst for hydrocarbon reactions, such as cracking, isomerization and aromatization, all based on carbocation intermediates ${ }^{19,20}$. The microporous structure of ZSM-5 zeolite impacts the shape-selective properties hindering both the hydrogen transfer reactions and the generation of polyaromatics, what contributes to increasing the $\mathrm{C}_{2}-\mathrm{C}_{4}$ olefin selectivity with low coke generation ${ }^{21}$. Furthermore, the threedimensional ZSM-5 zeolite structure entails facile diffusion of coke precursors to the outer surface of the grains, leading to high resistance toward poisoning of the active sites ${ }^{22}$. Nevertheless, the high viscosity and bulky molecular volume of polyethylenes requires a significantly enhanced porosity, and thus the accessibility of acid sites as well. The combination of the intrinsic acidity of the zeolites with a highly developed porosity typical of mesoporous materials, both gathered in hierarchical zeolites, offer unique advantages for the catalytic cracking of polyolefinic waste plastics into fuels ad chemicals. 
This work focuses on a detailed investigation of the structural, textural and acidic characteristics of hierarchical ZSM-5 zeolites, obtained with different desilication approaches, and the effect of those parameters on the reactivity in various cracking reactions of variable feedstock size and severity. The presence of PDA (pore-directing-agent) during desilication offers a greater mesoporosity development and higher acid strength when comparing it with pure $\mathrm{NaOH}$ treatment. The changes in acidity and porosity of the desilicated zeolites are followed on the basis of FTIR spectroscopy studies with the use of several probe molecules, as well as their catalytic performance in the cracking of $n$-decane and $1,3,5-$ tri-isopropylbenzene as model reactions. Linear $n$-decane easily penetrates the $10 \mathrm{MR}$ channels of the ZSM-5 zeolite. Therefore the catalytic activity in $n$-decane cracking can be correlated with the strength of all acid sites. On the other hand, the performance in 1,3,5-tri-isopropylbenzene cracking is correlated to the accessibility of protonic sites as determined by in-situ FTIR studies. Finally, the investigation is extended to the catalytic pyrolysis of LDPE and HDPE polymers that shows a linear correlation with the accessibility factors. 


\section{Experimental}

\subsection{Studied Materials}

Parent microporous ZSM-5 of Si/AI = 32 zeolite denoted hereafter as ZSM-5/32 was supplied by Zeolyst (CP 5524G). Desilication was carried out using $0.2 \mathrm{M}$ solutions of $\mathrm{NaOH}$ and $\mathrm{NaOH} \& \mathrm{TBAOH}$ (tetrabutylammonium hydroxide) mixture $(\mathrm{TBAOH} /(\mathrm{NaOH}+\mathrm{TBAOH})=0.4)$ at the temperature of $65^{\circ} \mathrm{C}$ or $80^{\circ} \mathrm{C}$ for $0.5 \mathrm{~h}$ or $5 \mathrm{~h}$. The samples notation gives a detailed description of the applied desilication conditions, i.e. desilicating medium $(\mathrm{NaOH}$ or $\mathrm{NaOH} / \mathrm{TBAOH})$, temperature $\left({ }^{\circ} \mathrm{C}\right)$ and treatment time $(\mathrm{h})$. After desilication, the suspension was cooled down in ice-bath, filtered and washed with distillate water until neutral $\mathrm{pH}$. Next fourfold $\mathrm{Na}^{+} / \mathrm{NH}_{4}{ }^{+}$ion-exchange with $0.5 \mathrm{M} \mathrm{NH}_{4} \mathrm{NO}_{3}$ was performed at 60 ${ }^{\circ} \mathrm{C}$ for $1 \mathrm{~h}$. Finally, the resulting samples were again filtrated, washed and dried at room temperature.

Powdery low-density and high-density polyethylenes were kindly supplied by Sabic.

\subsection{Characterization Techniques}

\subsubsection{Chemical analysis}

Si and Al concentrations in the parent and desilicated zeolites were determined by the ICP OES method with an Optima 2100DV (PerkinElmer) spectrometer.

\subsubsection{X-ray diffraction $(X R D)$}

Wide-angle XRD patterns were taken with a Rigaku Multiflex diffractometer equipped with $\mathrm{Cu} K \alpha$ radiation $(40 \mathrm{kV}, 40 \mathrm{~mA})$.

\subsubsection{X-ray photoelectron spectroscopy (XPS)}

The X-ray photoelectron spectra (XPS) were measured with a Prevac photoelectron spectrometer equipped with a hemispherical VG SCIENTA R3000 analyzer. The photoelectron spectra were measured using a monochromatized aluminum AlKa source $(E=1486.6 \mathrm{eV})$ and a low energy electron flood gun (FS40A-PS) to compensate the charge on the surface of nonconductive samples. The base pressure in the analysis chamber during the measurements was $5 \cdot 10^{-9} \mathrm{mbar}$. Spectra were recorded with constant pass energy of $100 \mathrm{eV}$ for the survey and for high resolution spectra. The binding energies were referenced to the Si $2 p$ core level $(103.0 \mathrm{eV})$. The surface composition and chemical environment were investigated on the basis of the peak areas and binding energies of $\mathrm{Al} 2 \mathrm{p}, \mathrm{Si} 2 \mathrm{p}$ and $\mathrm{O}$ 1s photoelectron peaks. The fitting of high-resolution spectra was carried out by the CasaXPS software.

\subsubsection{Nitrogen sorption measurements at $-196^{\circ} \mathrm{C}$}

Nitrogen sorption measurements were performed on a Quantachrome Autosorb-1-MP gas sorption instrument at $-196^{\circ} \mathrm{C}$. Prior to the measurements, all samples were degassed under high vacuum conditions for a duration of $16 \mathrm{~h}$ at $350^{\circ} \mathrm{C}$. The micropore volume were calculated based on the $t$-plot method, while the Brunauer-Emmet-Teller (BET) method was applied to determine the apparent specific surface area. Distributions of mesopore diameters were calculated via the Barrett-JoynerHalenda (BJH) algorithm using the adsorption branch ${ }^{23}$.

\subsubsection{TEM and SEM investigations}


Transmission electron microscopy was done with using a Philips $\mathrm{CM}-10$ microscope operating at 100 $\mathrm{kV}$. The samples under investigation were ultrasonically dispersed in 2-propanol and then transferred onto carbon coated copper grids.

Scanning electron microscopy was done using of a Philips XL 30 microscope.

\subsubsection{IR spectroscopic studies}

Prior to FTIR studies, the materials were pressed into the form of self-supporting discs (ca. 5-10 $\mathrm{mg} / \mathrm{cm}^{2}$ ) and pre-treated in situ in an IR cell at $500{ }^{\circ} \mathrm{C}$ under vacuum conditions for 1 hour. Spectra were recorded with a Bruker Vertex 70 spectrometer equipped with a MCT detector. The spectral resolution was set at $2 \mathrm{~cm}^{-1}$. All the spectra presented in this work were normalized to $10 \mathrm{mg}$ of sample. The $\mathrm{CO}$ adsorption was performed at $-100^{\circ} \mathrm{C}$. Total concentration of $\mathrm{Br} \varnothing n s t e d$ and Lewis acid sites was determined in quantitative IR studies of pyridine (Py) sorption at $170{ }^{\circ} \mathrm{C}$ according to the procedure described elsewhere ${ }^{12,24}$. The values of $0.10 \mathrm{~cm}^{2} / \mu \mathrm{mol}$ and $0.07 \mathrm{~cm}^{2} / \mu \mathrm{mol}$ were used for the $1450 \mathrm{~cm}^{-}$ ${ }^{1}$ band of pyridine coordinatively bonded to Lewis sites (PyL) and for the $1545 \mathrm{~cm}^{-1}$ band of pyridinium ion $\left(\mathrm{PyH}^{+}\right)$, respectively. Pyridine was supplied by Sigma-Aldrich ( $\left.\geq 99.8 \%\right)$.

The concentrations of the Brønsted and Lewis acid sites accessible for bulky pivalonitrile and collidine (hereafter denoted as Pn and Coll, respectively) were also achieved from quantitative studies described elsewhere ${ }^{25,26}$, respectively. The pivalonitrile (98\%, Sigma Aldrich) was adsorbed on the zeolites at room temperature followed by $20 \mathrm{~min}$. evacuation at the same temperature, in order to remove the excess of physisorbed Pn probe molecules. The concentration of the Brønsted and Lewis acid sites detected by the Pn was calculated from the maximum intensities (peak height) of the respective bands at $2277 \mathrm{~cm}^{-1}$ and $2305 \mathrm{~cm}^{-1}$ and their extinction coefficient $\left(0.11\right.$ and $0.15 \mathrm{~cm}^{2} \mu \mathrm{mol}^{-}$ ${ }^{1}$, resp.). The zeolites were contacted with collidine ( $\geq 97 \%$, Sigma Aldrich) vapor at room temperature, then physisorbed probe molecules were removed by evacuation at $200{ }^{\circ} \mathrm{C}$. The concentration of the protonic sites detected by the Coll was calculated from the maximum intensities (peak height) of the Coll $\mathrm{H}^{+}$bands at $1635 \mathrm{~cm}^{-1}$ and its extinction coefficient equals to $0.62 \mathrm{~cm}^{2} \mu \mathrm{mol}^{-1}$.

\subsection{Catalytic tests of model molecules cracking}

The cracking experiments were performed in a MAT (Micro Activity Test) unit ${ }^{27}$. Pellets of zeolites were crushed and sieved; fraction of the $0.59-0.84 \mathrm{~mm}$ was taken for cracking reactions. Catalytic experiments were carried out preserving the amount of catalyst (cat) constant and varying the feeds amounts (oil). Three cracking reactions with different cat-to-oil ratios of 1,3,5-tri-iso-propylbenzene (TIPB) were performed at $500{ }^{\circ} \mathrm{C}$ and for $60 \mathrm{~s}$ time on stream (TOS), with $200 \mathrm{mg}$ of catalyst. For $n$ decane cracking at $500{ }^{\circ} \mathrm{C}$ and for $60 \mathrm{~s}$ TOS, $300 \mathrm{mg}$ of catalyst was diluted in $2.5 \mathrm{~g}$ of inert silica, and four cracking reactions with different cat-to-oil ratios were performed.

Kinetic rate constants $(k)$ were calculated by fitting the conversions $(X)$ to a first-order kinetic equation for a plug flow reactor (1) for $n$-decane and TIPB, assuming that the deactivation is enclosed in the kinetic constant and taking into account the volumetric expansion factor (2),

$$
\begin{aligned}
& k=-\left(\text { cat oil }{ }^{-1} \mathrm{TOS}\right)^{-1}[\varepsilon \mathrm{X}+(1+\varepsilon) \ln (1-\mathrm{X})] \\
& \varepsilon=(\text { Emolar selectivities of products })-1
\end{aligned}
$$




\subsection{Catalytic tests of LDPE and HDPE cracking}

The catalytic cracking of low-density and high-density polyethylenes (PES) was evaluated by thermogravimetric analysis in a Mettler-Toledo TGA/SDTA851e analyzer. A stock mixture of the ground polymer and the zeolite powder was prepared in a ratio of polymer:zeolite $=3: 1$; this was prepared by intimately mixing in an Agatha mortar. A certain portion of the mixture (typically 5-10 mg) was loaded in a $70 \mu \mathrm{l} \alpha-\mathrm{Al}_{2} \mathrm{O}_{3}$ crucible and weighted with a 5-digits Mettler Toledo balance before the analysis. The sample was placed in the furnace, the analytic gas was switched on and the temperature was raised from 30 to $600{ }^{\circ} \mathrm{C}$ at a heating rate of $5^{\circ} \mathrm{C} / \mathrm{min}$ under a nitrogen flow of $80 \mathrm{~mL} / \mathrm{min} \mathrm{STP}$. The conversion was calculated by deducing the catalyst weight and moisture content. 


\section{Results and Discussion}

\subsection{Structural and textural characterization}

The X-ray diffraction patterns of parent and desilicated zeolites exhibit well resolved reflections representative for the MFI structure; no significant changes in position or intensity of the reflections can be noticed (Figure 1). The crystallinity values of the desilicated samples (Table 1) confirm the preservation of the zeolite structure during alkaline treatment; though changes in crystallinity can be appreciated as discussed below. Independently from the treatment conditions, no amorphous phase has been detected; only a slight drop of crystallinity with treatment time was observed. The lowest value of crystallinity was found for the material treated with $\mathrm{NaOH}$ at $80^{\circ} \mathrm{C}$ for $5 \mathrm{~h}$ while the TBAOHtreated samples showed slightly higher values of crystallinity. The analysis of the chemical composition for the desilicated zeolites suggests clear differences between $\mathrm{NaOH}$ and those obtained by $\mathrm{NaOH} \& \mathrm{TBAOH}$ treatment. Regardless the treatment conditions, i.e. temperature and time, the higher $\mathrm{Si} / \mathrm{Al}$ ratio values were observed always for samples treated with $\mathrm{NaOH} \& \mathrm{TBAOH}$. The extent of silicon extraction resulting from the use of different desilicating agents is generally accompanied by changes in crystallinity, i.e. the higher the Si extraction the lower the crystallinity. A similar conclusion has been drawn also for more extensive desilication processes in the case of both medium and high silica zeolites 9,12 .

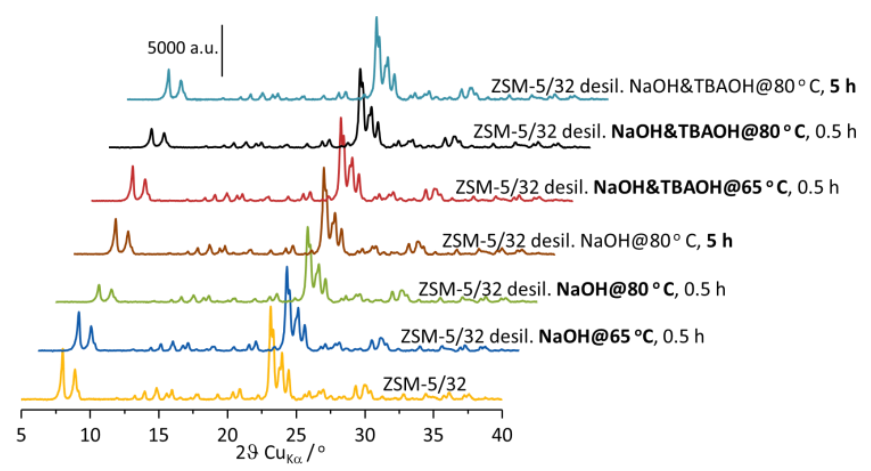

Figure 1. X-ray diffraction patterns of parent and desilicated ZSM-5 zeolites.

Besides the chemical composition of the bulk, for cracking of large molecules, the composition of the zeolite grains' surface is equally important. Thus, the XPS studies of parent and desilicated zeolites were also performed. In the case of the parent zeolite, the $\mathrm{Si} / \mathrm{Al}_{\text {surf }}$ value points on a slightly higher concentration of aluminum atoms on the grain's surface. It is worth mentioning that desilication process proceeds, according to a widely accepted mechanism, ${ }^{28}$ assuming that silicon atoms in the neighborhood of aluminum atoms are the less prone for extraction during alkaline treatment. Furthermore, for desilicated zeolites using $\mathrm{NaOH}$ the $\mathrm{Si} / \mathrm{Al}_{\text {surf }}$ values imply that neither an enhanced silicon extraction from surface nor significant realumination process occurred during the modification. On the other hand, for the modified zeolites with $\mathrm{NaOH} \& \mathrm{TBAOH}$, a more homogenous distribution of silicon and aluminum in the grain volume was found, as it can be derived from the similar Si/Albulk and $\mathrm{Si} / \mathrm{Al}_{\text {surf }}$ values. The enhanced amount of aluminum on the grain's surface can be responsible for the better catalytic performance in reactions involving branched molecules. It is important to underline that the presented results can only be referred to changes in composition of the bulk and grains' surface, not necessarily to the surface of mesopores created during desilication. Further discussion on the presence of different types of centers on zeolite surface will be done with respect to FTIR studies using different probe molecules (see Section 3.2). 
Table 1. Chemical composition of the bulk and surface, crystallinity and textural properties derived from $\mathrm{N}_{2}$ physisorption of the parent and desilicated ZSM-5 zeolites.

\begin{tabular}{|c|c|c|c|c|c|c|c|c|}
\hline & $\mathrm{Si} / \mathrm{Al}_{\mathrm{bulk}^{a}}{ }^{\mathrm{a}}$ & $\begin{array}{c}\mathrm{Al}^{\mathrm{a}} \\
/ \mu \mathrm{mol} \cdot \mathrm{g}^{-1}\end{array}$ & $\mathrm{Si} / \mathrm{Al}_{\text {surf }}$ & $\begin{array}{c}\text { Cryst. } \\
/ \%\end{array}$ & $\begin{array}{c}\mathrm{S}_{\mathrm{BET}} \\
/ \mathrm{m}^{2} \cdot \mathrm{g}^{-1}\end{array}$ & $\begin{array}{c}V_{\text {micro }} \\
/ \mathrm{cm}^{3} \cdot \mathrm{g}^{-1}\end{array}$ & $\begin{array}{c}V_{\text {meso }} \\
/ \mathrm{cm}^{3} \cdot \mathrm{g}^{-1}\end{array}$ & $\begin{array}{l}S_{\text {meso }} \\
/ \mathrm{m}^{2} \cdot \mathrm{g}^{-1}\end{array}$ \\
\hline ZSM-5/32 & 32 & 478 & 25 & 100 & 377 & 0.17 & 0.06 & 40 \\
\hline ZSM-5/32 desil. NaOH@65 C, 0.5 h & 20 & 741 & 14 & 87 & 454 & 0.15 & 0.21 & 145 \\
\hline ZSM-5/32 desil. NaOH@80 C, 0.5 h & 18 & 819 & 15 & 86 & 446 & 0.15 & 0.20 & 135 \\
\hline ZSM-5/32 desil. NaOH@80 C, 5 h & 18 & 819 & 14 & 90 & 435 & 0.16 & 0.28 & 98 \\
\hline ZSM-5/32 desil. NaOH\&TBAOH@65 C, 0.5 h & 24 & 622 & 20 & 89 & 415 & 0.12 & 0.20 & 175 \\
\hline ZSM-5/32 desil. NaOH\&TBAOH@80 C, 0.5 h & 22 & 676 & 20 & 88 & 383 & 0.09 & 0.23 & 193 \\
\hline ZSM-5/32 desil. NaOH\&TBAOH@80 C, 5 h & 23 & 648 & 19 & 94 & 405 & 0.10 & 0.32 & 185 \\
\hline
\end{tabular}

Equally important to changes in the structural properties are the textural parameters (Figures 2, 3 and Table 1). As a result of desilication process, the major changes are observed in mesopore surface area. The development of a mesopore system in the zeolite grains leads to the enhancement of $S_{\text {meso }}$ which attains values as high as 145 and $193 \mathrm{~m}^{2} \cdot \mathrm{g}^{-1}$ for samples treated with $\mathrm{NaOH}$ and $\mathrm{NaOH} \& \mathrm{TBAOH}$, respectively, compared to $40 \mathrm{~m}^{2} \cdot \mathrm{g}^{-1}$ for the parent zeolite. Together with the enhancement of mesopore surface area, the desilication process influences also the micropore volume. The alkaline leaching typically leads to a slight drop of the micropore volume which is usually assigned either to deposition of extra-framework material inside the micropores or to the loss of crystallinity. As mentioned above, the structure of the desilicated zeolites was preserved but there is a drop of about $10 \%$ crystallinity, thus the observed drop of micropore volume is probably due to: 1) drop in crystallinity and 2) the presence of extra-framework material inside zeolite channels. The development of a mesopore system was also confirmed by the changes in shape of the $\mathrm{N}_{2}$ adsorption-desorption isotherms (Figures 2 and 3). For a typically microporous ZSM-5/32 sample, the isotherm represents a type-I in the IUPAC classification, while for the desilicated materials the type-IV of micro/mesoporous materials is observed, displaying a well-defined hysteresis. Additionally, the samples treated with $\mathrm{NaOH} \& \mathrm{TBAOH}$ display a wider hysteresis loop in the isotherm with a closure point around $\mathrm{p} / \mathrm{p}_{0}=0.4$. This wider hysteresis, and abrupt closure point, have been related to the presence of constricted mesopores in which nitrogen only can access through micropores or small mesopores of sizes $\leq 4 \mathrm{~nm}$ ( $3.8 \mathrm{~nm}$ according to the $\mathrm{BJH}$ model); thus the adsorbate is not fully accessible directly from the surface of the crystals. This effect is also observed for the $\mathrm{NaOH}$-treated samples, but it is less remarkable. The pore size distributions furthermore confirm the hierarchical porosity. Apart from higher values of $S_{\text {meso }}$ for $\mathrm{NaOH} \& \mathrm{TBAOH}$ treated samples, another advantage over the $\mathrm{NaOH}$ counterparts is the presence of mesopores with more uniform sizes in the range from 3 to $20 \mathrm{~nm}$. NaOH-treated zeolites possess mesopores larger than $10 \mathrm{~nm}$ with a broad distribution of sizes between 10 and $40 \mathrm{~nm}$.

Additional information on the properties of the generated mesoporosity was drawn from the SEM and TEM images of the parent and two representative zeolites desilicated with $\mathrm{NaOH}$ or $\mathrm{NaOH} \& \mathrm{TBAOH}$ (65 ${ }^{\circ} \mathrm{C}, 0.5 \mathrm{~h}$ ). The SEM images evidenced no significant changes in the size or the shape of the grains provoked by desilication. The TEM analysis proved that the desilication process was an effective path for the generation of intraparticle porosity. The NaOH\&TBAOH-treatment assured more uniform, across the grain, formation of the mesopores. Leaching with $\mathrm{NaOH}$ created mesopores of larger size and more irregularly distributed in the zeolite grains. 

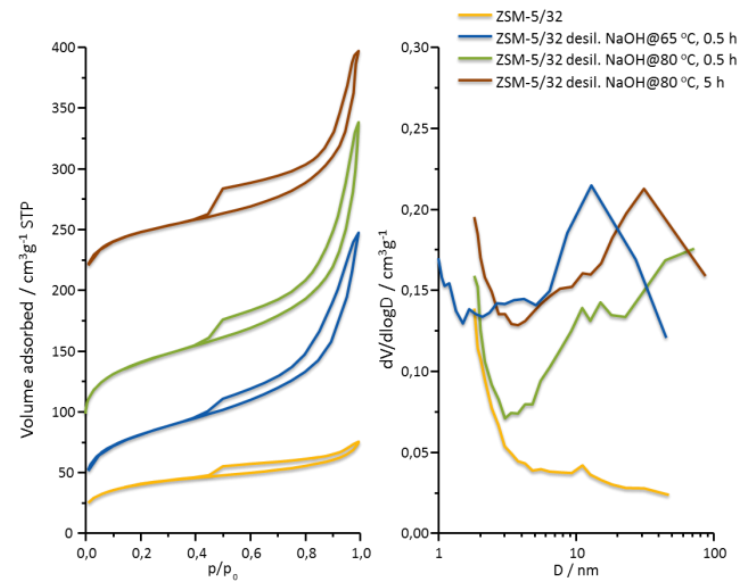

Figure 2. Left) $\mathrm{N}_{2}$ adsorption-desorption isotherms and right) $\mathrm{BJH}$ pore size distributions for the parent and desilicated zeolites, using $\mathrm{NaOH}$.


Figure 3. Left) $\mathrm{N}_{2}$ adsorption-desorption isotherms and right) $\mathrm{BJH}$ pore size distributions for the parent and desilicated zeolites, using $\mathrm{NaOH} \& \mathrm{TBAOH}$.
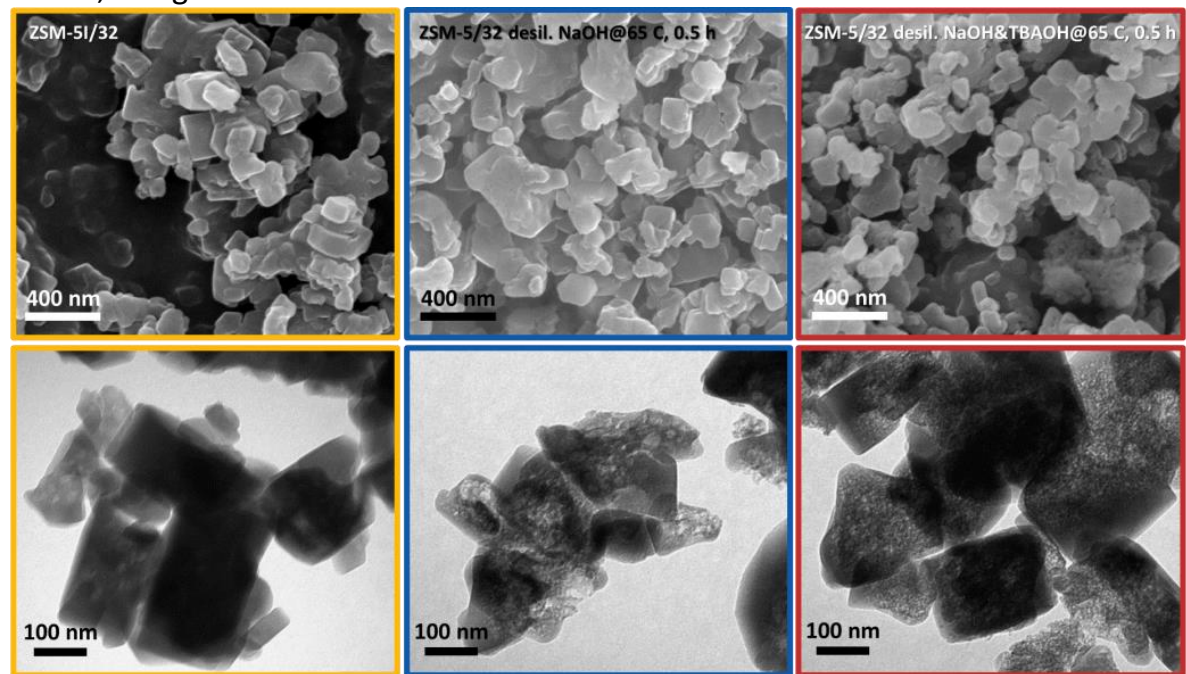

Figure 4. SEM (top) and TEM (bottom) images of the parent (left) and two representative samples treated with $\mathrm{NaOH}$ (middle) and $\mathrm{NaOH} \& \mathrm{TBAOH}$ (right), both treated at $65^{\circ} \mathrm{C}, 0.5 \mathrm{~h}$.

\subsection{Acidity and accessibility of sites}

Investigation of the hydroxyl groups spectra of parent and desilicated zeolites allows for distinguishing four types of bands: the $3500 \mathrm{~cm}^{-1}$ broad band of the silanols nests, the $3605 \mathrm{~cm}^{-1}$ band of the acidic $\mathrm{Si}(\mathrm{OH})$ Al groups, the $3730 \mathrm{~cm}^{-1}$ band of $\mathrm{Si}(\mathrm{OH})$ groups in defects and finally the $3742 \mathrm{~cm}^{-1} \mathrm{Si}(\mathrm{OH})$ groups of silanols on the external surface of the grains and mesopores. The desilication process using $\mathrm{NaOH}$ 
and $\mathrm{NaOH} \& \mathrm{TBAOH}$ leads to visible increase in the intensity of the acidic hydroxyls band which can be related to enhanced content of aluminum atoms in zeolite framework. The significant population enhancement of silanols was concluded from the increased intensity of $3742 \mathrm{~cm}^{-1}$ band and was directly associated with the development of the mesopore system. Since higher values of mesopore surface area were observed for samples treated with $\mathrm{NaOH} \& \mathrm{TBAOH}$, a higher intensity of the $\mathrm{Si}(\mathrm{OH})$ bands for these samples were noticed. Additionally, the $3730 \mathrm{~cm}^{-1} \mathrm{Si}(\mathrm{OH})$ band, representing silanols in defects, is especially well distinguishable in the case of zeolites treated with $\mathrm{NaOH \& TBAOH}$. Thus, together with higher values of $S_{\text {meso }}$ it can be concluded that the porosity generated in zeolites treated with $\mathrm{NaOH} \& \mathrm{TBAOH}$ represents rather the intraparticle character with higher wall curvature entailing the formation of hydrogen bonded silanols represented by the $3730 \mathrm{~cm}^{-1}$ band. Similar conclusion, the dependence between the wall curvature of mesopores with type of observed silanols on mesopores surface has been observed for SBA-15 materials ${ }^{29}$. Finally, it is worth mentioning that, independently from the desilicating agent, the alkaline treatment results in removal of highly linked silanols in so called silanols nests represented by the $3500 \mathrm{~cm}^{-1}$ band. The preferential removal of silicon depending on type of neighboring atoms has been already studied by IR and NMR methods ${ }^{14}$. It has been proven that the aluminum presence has a protective influence on the neighboring silicon atoms.



Figure 5. IR spectra of the $\mathrm{OH}$ groups for parent and desilicated ZSM-5 zeolites $(\mathrm{Si}(\mathrm{OH})$ groups for chosen zeolites in inset)

Further characteristic features of the acidic sites for the parent and desilicated zeolites involve FTIR quantitative studies of pyridine $(0.57 \mathrm{~nm})$, pivalonitrile $(0.65 \mathrm{~nm})$ and collidine $(0.74 \mathrm{~nm})$ sorption. The use of probe molecules with different kinetic diameter assures the comparison of the changes not only in acidity but also in accessibility of the acid sites after the desilication process. The total concentration of Brønsted and Lewis acid sites was determined by quantitative IR studies of pyridine as probe molecule. As can be noticed (Table 2) the desilication process leads to increase of concentration of both Brønsted and Lewis acid sites. With respect to changes in acidity after desilication, the most prominent changes were recognized for samples treated with $\mathrm{NaOH}$ only, in line with the most significant changes in Si/Al ratios. The total concentrations of acid sites $\left(C_{B}+C_{L}\right)$ determined with pyridine correspond to the values of the Al content obtained from the chemical analysis; thus it can be 
deduced that each $\mathrm{Al}$ atom is able to form either acidic $\mathrm{Si}(\mathrm{OH}) \mathrm{Al}$ group or Lewis acid site easily accessible by the probe molecule.

The $\mathrm{CO}$ sorption studies provides insight on the nature and strength of both Brønsted and Lewis acid sites. The $\mathrm{CO}$ adsorbed on the studied zeolites show two bands: the $2175 \mathrm{~cm}^{-1}$ band of $\mathrm{CO}$ interacting with the $\mathrm{Si}(\mathrm{OH}) \mathrm{Al}$ groups and the $2230 \mathrm{~cm}^{-1}$ band originating from the interaction of $\mathrm{CO}$ with Lewis acid sites of high strength formed in the dehydroxylation process (Figure 6). Since the enhancement of the Brønsted acid sites strength, in the presence of extra-framework electron acceptor acid sites, has been widely reported, the highest contribution of Lewis acid sites observed for $\mathrm{NaOH \& TBAOH-treated}$ sample would guarantee an enhancement in its catalytic performance.

Table 2. Concentration of aluminum (ICP) and Brønsted and Lewis acid sites interacting with pyridine, pivalonitrile and collidine probe molecules in parent and desilicated ZSM-5 zeolites

\begin{tabular}{ccccccccc}
\hline & $\begin{array}{c}\mathrm{Al} \\
/ \mu \mathrm{mol} \cdot \mathrm{g}^{-1}\end{array}$ & $\begin{array}{c}\mathrm{PyH}^{+} \\
/ \mu \mathrm{mol} \cdot \mathrm{g}^{-1}\end{array}$ & $\begin{array}{c}\mathrm{PyL} \\
/ \mu \mathrm{mol} \cdot \mathrm{g}^{-1}\end{array}$ & $\begin{array}{c}\mathrm{C}_{\mathrm{B}}+\mathrm{C}_{\mathrm{L}} \\
/ \mu \mathrm{mol} \cdot \mathrm{g}^{-1}\end{array}$ & $\begin{array}{c}\mathrm{PnH}{ }^{+} \\
/ \mu \mathrm{mol} \cdot \mathrm{g}^{-1}\end{array}$ & $\begin{array}{c}\mathrm{PnL} \\
/ \mu \mathrm{mol} \cdot \mathrm{g}^{-1}\end{array}$ & $\begin{array}{c}\text { Coll } \\
/ \mu \mathrm{mol} \cdot \mathrm{g}^{-1}\end{array}$ & $\begin{array}{c}\Delta v_{\mathrm{CO} . . \mathrm{OH}} \\
/ \mathrm{cm}^{-1}\end{array}$ \\
\hline ZSM-5/32 & 478 & 450 & 30 & 480 & 54 & 7 & 22 & 315 \\
\hline ZSM-5/32 desil. NaOH@65 C, 0.5 h & 741 & 575 & 205 & 780 & 187 & 92 & 100 & 305 \\
ZSM-5/32 desil. NaOH@80 C, 0.5 h & 819 & 630 & 180 & 810 & 122 & 49 & 137 & 306 \\
ZSM-5/32 desil. NaOH@80 C, 5 h & 819 & 677 & 111 & 788 & 151 & 63 & 124 & 307 \\
\hline ZSM-5/32 desil. NaOH\&TBAOH@65 C, 0.5 h & 622 & 480 & 160 & 640 & 218 & 106 & 120 & 312 \\
ZSM-5/32 desil. NaOH\&TBAOH@80 C, 0.5 h & 676 & 545 & 132 & 677 & 316 & 130 & 219 & 309 \\
ZSM-5/32 desil. NaOH\&TBAOH@80 C, 5 h & 648 & 511 & 160 & 671 & 221 & 93 & 118 & 310 \\
\hline
\end{tabular}

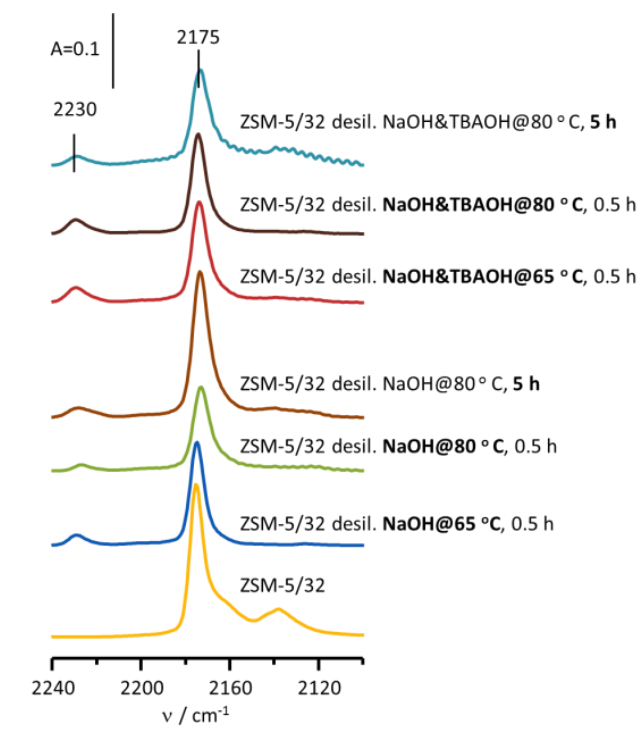

Figure 6. IR spectra of $\mathrm{CO}$ sorption at $-100^{\circ} \mathrm{C}$ for the parent and desilicated ZSM-5 zeolites

Cracking of large and branched molecules requires not only the tuned acidity but also the enhanced accessibility of the sites. Thus, the IR studies involving the sorption of pivalonitrile and collidine were performed. As can be seen from results presented in Table 2 the desilication ensured enhanced accessibility of the acid sites, what is especially well seen for samples treated with $\mathrm{NaOH} \& T B A O H$. The use of pivalonitrile as probe molecule allows for assessing the number of acid sites accessible from external surfaces of the grains, mesopores and from pore mouths of micropores. For pivalonitrile the accessibility of Brønsted acid sites is maintained at level of $\sim 25 \%$ (19-32\%) and $~ 50 \%$ (43-58\%) for 
$\mathrm{NaOH}$ and $\mathrm{NaOH} \& \mathrm{TBAOH}$ treated samples respectively, manifesting that alkaline treatment performed in presence of TBAOH assured superior properties of the obtained materials over those obtained with use of $\mathrm{NaOH}$ only. Besides, the results concerning the accessibility of Lewis acid sites allow for drawing interesting conclusions. Despite the lower $\mathrm{Si} / \mathrm{Al}_{\text {surf }}$ values for samples treated with $\mathrm{NaOH}$, the accessibility of both protonic and aprotonic sites is distinctly lower than for the $\mathrm{NaOH} \& \mathrm{TBAOH}$-treated zeolites. This may suggest that for the NaOH\&TBAOH treated samples the majority of sites are accessible from the intraparticle mesoporous surface, being outside of the detection limit for the XPS method. The high values of accessibility of Lewis acid sites confirm their high dispersion on the surface of the mesopores. These highly dispersed Lewis acid sites of high strength, as concluded from CO sorption studies, are expected to have positive influence on the catalytic activity.

The assessment of the accessibility of the Brønsted acid sites was also performed by IR spectroscopic studies of collidine sorption. In the case of this probe molecule having a bigger kinetic diameter, which can interact only with sites located on the more external surface area, again the higher accessibility of acid sites is recognized for samples treated with $\mathrm{NaOH} \& \mathrm{TBAOH}$. While for samples treated with $\mathrm{NaOH}$ the accessibility of acid sites for collidine reaches $22 \%$, the NaOH\&TBAOH-modified zeolites allows for an enhancement of the accessibility to level up to $40 \%$. An exception occurs for the harsher conditions ( $5 \mathrm{~h}$ treatment) where similar accessibilities were observed. This can be related to the Al enrichment, not detected by XPS, leading to an Al-rich shell located in the outer of the zeolite grain with pore restrictions (not detected by $\mathrm{N}_{2}$ physisorption). The Al-shell was demonstrated by Groen et al. ${ }^{30}$

The dependence of the accessibility factors for pivalonitrile and collidine as probe molecules with respect to mesopores surface area is presented in Figure 7 . The accessibility factors ( $A F_{p n}$ and $A F_{\text {coll }}$ ) were defined as the ratio of acid sites concentration accessible to bulky molecule (collidine or pivalonitrile) to total concentration of acid sites measured by pyridine sorption ${ }^{25,31}$. The acid sites accessibility for both probe molecules, as shown in Figure 7, demonstrates a clear correlation with the mesopore surface area. Such an enhanced accessibility of the acid sites was confirmed in the cracking of TIPB (Section 3.3).

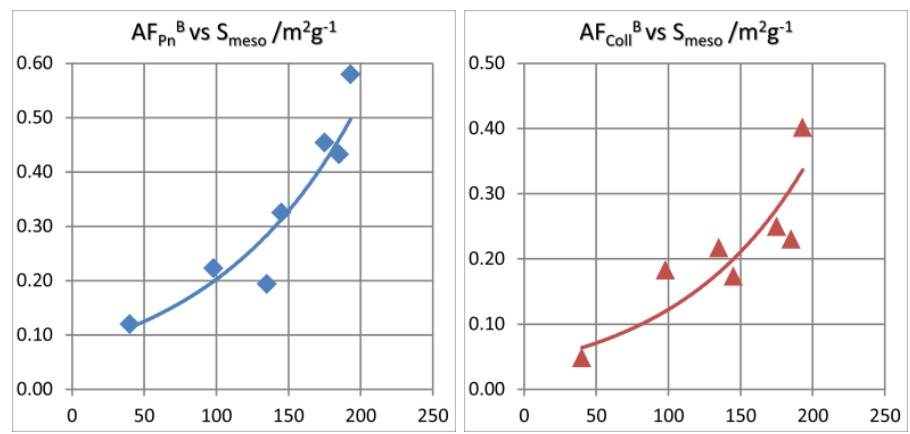

Figure 7. Accessibility factors for pivalonitrile $(\Delta)$ and collidine $(\mathbf{\Delta})$ as probe molecules depending on the mesopores surface area of parent and all desilicated ZSM- 5 zeolites.

The last aspect of acidity characterization concerns the determination of strength of the acid sites. Similarly as the accessibility features, the acid sites strength should also find a direct reflection in the catalytic cracking performance of the studied zeolites. Information on the changes in the acid strength were derived from the values of the frequency shifts $\Delta v_{\text {со..он }}$ of the band of the Si(OH)Al groups interacting with the $\mathrm{CO}$ molecule (Table 2). The desilication process led to noticeable changes in the strength of $\mathrm{Si}(\mathrm{OH}) \mathrm{Al}$ groups: a drop of $\Delta v_{\mathrm{CO}}$. OH is clearly visible. This decrease in the acid strength of 
the protonic sites can be related to (i) the decrease of Si/Al ratio of the desilicated zeolites and (ii) to the extraction of $\mathrm{Al}$ atoms from the most acidic $\mathrm{Si}(\mathrm{OH}) \mathrm{Al}$ groups due to their low stability in tetrahedral framework positions. Such an interpretation has been proposed in our earlier study of desilicated BEA zeolites ${ }^{32}$ and is also found in the work of Lee et al. ${ }^{33}$, reporting a considerable reduction of the amount of strong acid sites after the introduction of mesopores in the structure of ZSM- 5 zeolite. The changes in the acid strength upon desilication will be also discussed with regard to the catalytic cracking reactions (Section 3.3).

\subsection{Catalytic performance in $n$-decane and TIPB cracking probe molecules}

The cracking reactions of TIPB (1,3,5-tri-iso-propylbenzene) and $n$-decane were performed in order to evaluate the impact of the textural and acidic properties resulting from desilication on the catalytic performance; the changes are compared to the untreated ZSM-5 zeolite. Three catalytic parameters were evaluated: conversion at various oil/cat ratios, coke content and kinetic constant. The catalytic activity in the cracking of TIPB, a branched and bulky molecule (kinetic diameter $0.95 \mathrm{~nm}$ ) being not able to penetrate the 10-MR channels of ZSM-5 zeolite, should reflect the alterations in the textural parameters followed by the changes in the accessibility of the acid sites. On the other hand, the activity in the catalytic cracking of $n$-decane is expected to reflect the changes in the intrinsic Brønsted acidity. The cracking of $n$-decane, able to freely diffuse through the micropores, is highly demanding on the concentration and the strength of the acid sites. The desilicated ZSM-5 zeolites were supposed to overcome the limitations of the microporous counterpart demonstrating the same trends as observed in the FTIR and textural studies results. The samples treated under $\mathrm{NaOH}$ and $\mathrm{NaOH} \& \mathrm{TBAOH}$ at $65^{\circ} \mathrm{C}$ for $0.5 \mathrm{~h}$ were the most representative examples of the desilicated zeolites and will be further discussed in this section.
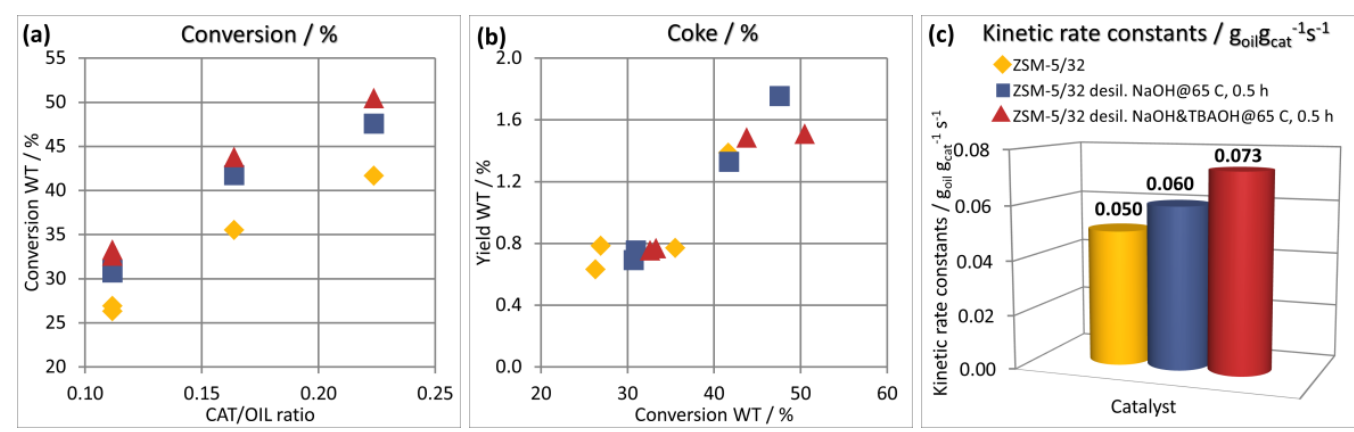

Figure 8. (a) Conversion, (b) yield of coke and (c) kinetic rate constants ( $k_{\text {TIPB }}$ ) derived from the TIPB catalytic cracking at $500^{\circ} \mathrm{C}$ and $60 \mathrm{~s}$ time on stream over the parent and desilicated ZSM- 5 zeolites

The catalytic activity in the cracking of TIPB over the parent zeolite and those desilicated with use of $\mathrm{NaOH}$ or $\mathrm{NaOH} \& \mathrm{TBAOH}$ demonstrated an enhancement of the conversion for the modified materials (Figure 8a). A strong correlation is observed between catalytic activity of the hierarchical ZSM-5 zeolites and their textural properties, i.e. the mesopore surface area and the mesopore volume, as well as the accessibility of the acid sites have a positive impact on the conversion levels at various cat/oil ratio. It can be noticed that the highest catalytic activity is observed for the sample treated with $\mathrm{NaOH} \& \mathrm{TBAOH}$. This fact further supports the conclusions withdrawn from the textural parameters and FTIR studies, which point out on a superior type of mesoporosity, characterized by smaller size and a narrower diameter distribution. As mentioned, the catalytic activity can be also associated with the accessibility factors of the acid sites estimated from pivalonitrile and collidine molecules; the observed 
order of increasing conversion correlates with the enhancement of the accessibility factors. The micro/mesoporous character of the desilicated zeolites allow for a similar formation of coke deposit at higher conversion in comparison to the parent zeolite (Figure 8b).

The catalytic activity was also evaluated on the basis of kinetic rate constants, which demonstrate the same order of increase as the accessibility factors and mesopore surface areas (Figure 8c); strictly speaking the comparison should be made with Coll accessibility as having the most comparable size with respect to TIPB. The highest $k_{\text {TIPB }}$ value is observed for the NaOH\&TBAOH-treated zeolite. In spite of the drop of acid strength, the generation of the secondary system of mesopores leads to higher accessibility of the protonic sites for TIPB. As the catalytic activity increased with the accessibility of Coll protonic sites it could be anticipated that the mesopores system promoted the diffusion of the bulky 1,3,5-tri-isopropylbenzene and, finally, provided higher activity of the hierarchical zeolites. Therefore, not only the acidity of the protonic sites but their improved accessibility is evidenced as a predominant factor influencing the TIPB cracking. It has to be remarked that the mesoporous ZSM- 5 zeolite obtained by $\mathrm{NaOH} \& \mathrm{TBAOH}$ treatment presented a high activity for the cracking of TIPB despite the presence of restricted mesoporosity, as indicated by the nitrogen desorption isotherms. This occluded mesoporosity, when reported for the conversion of methanol to hydrocarbons did not improve the lifetime and was attributed to the quality of mesopores that only could be reached by the reactants through the micropores ${ }^{34}$. The reaction temperatures for TIPB cracking $\left(500{ }^{\circ} \mathrm{C}\right)$ are higher than those applied for the methanol to hydrocarbon reaction $\left(400-450^{\circ} \mathrm{C}\right)$. Thus for the cracking of TIPB, i.e. reaction very sensitive to the presence of mesopores, the mesoporosity is active, what suggests that at least part of the mesopore system is accessible. An important observation is the fact that a 4-fold increase of mesopore surface area for the desilicated samples delivers an enhancement of the kinetic rate constants up to $40 \%$ only. This suggests the presence of restricted porosity, possibly induced by the Al-rich shell, in addition to the lower acid strength of the sites for ZSM-5 zeolite with $\mathrm{Si} / \mathrm{Al}=32$. An opposite effect was reported for highly siliceous zeolite ZSM-5 (Si/Al=164), were the formation of the Al-rich shell is less probable ${ }^{9,35}$. Thus the influence of mesoporosity for high silica ZSM5 (Si/Al=164) has a higher impact on the catalytic performance, e.g. kinetic rate constants of the TIPB cracking. The enhanced activity of highly siliceous ZSM-5 (Si/Al=164) was ruled not only by the developed mesopore surface area but also by high acid strength of the sites due to high Si/Al ratio.

The catalytic activity of ZSM-5 zeolites in the cracking of $n$-decane, with a kinetic size enabling nonrestricted diffusion through the 10-MR channels, is mainly determined by the concentration and strength of Brønsted acid centers ${ }^{36,37}$. Indeed, the desilication process leading to a drop of strength of the acid sites also causes a decrease in the conversion for the cracking of $n$-decane (Figure 9a). This effect is especially pronounced for the zeolite treated with $\mathrm{NaOH}$ only, for which a $10 \%$ of a decreased conversion was recognized. In the case of $\mathrm{NaOH} \& \mathrm{TBAOH}$-treated zeolites, the drop of both the acid strength and the conversion is less significant. A lower strength of acid sites was proven in FTIR studies of CO sorption discussed previously (Section 3.2). The observed decrease in the conversion demonstrates that despite the enhanced concentration of the protonic sites, the acid strength is a determining factor for the activity in the cracking of $n$-decane. The process of catalytic cracking of $n$ decane takes place mainly in the micropore system, thus the presence of mesopores can limit the confinement effect and negatively influence the activity of the catalytic cracking ${ }^{38}$. Despite the generation of a significant mesopore surface area through the desilication process, the amount of formed coke deposits for $n$-decane cracking is being maintained, or slightly higher, than the parent zeolite (Figure 9b). Additionally, Lewis acid sites have been considered as active species playing a role 
in the formation of carbonaceous deposits during the catalytic reaction ${ }^{39,40}$. The same trend as for conversion is also seen for the experimentally determined kinetic rate constants, what further confirms the drawn conclusions (Figure 9c). Clearly visible are the advantages of the $\mathrm{NaOH} \& \mathrm{TBAOH}$ over the $\mathrm{NaOH}$ treatments; still the highest performance is observed for the parent zeolite.
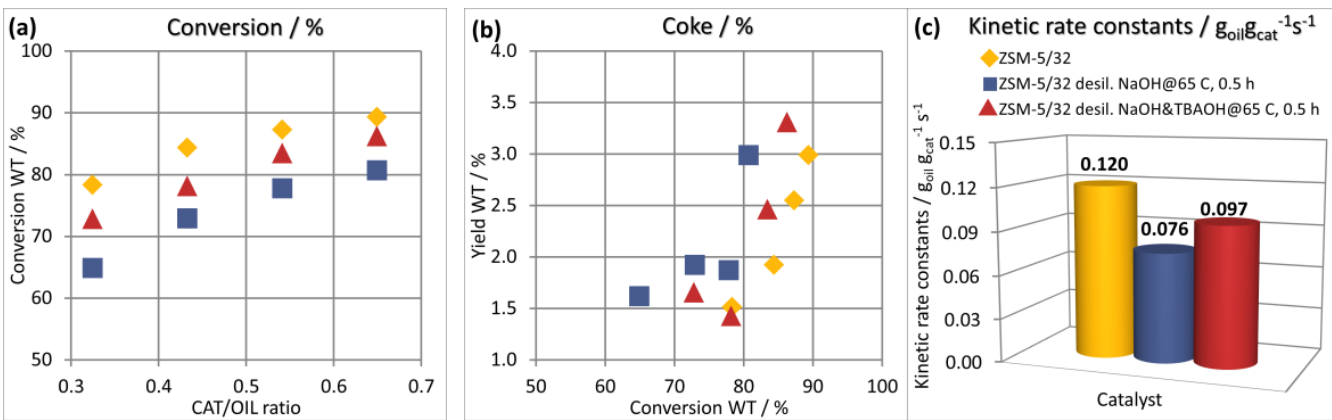

Figure 9. (a) Conversion, (b) yield of coke and (c) kinetic rate constants $\left(k_{n-c 8}\right)$ from results of $n$-decane catalytic cracking at $500^{\circ} \mathrm{C}$ and $60 \mathrm{~s}$ time on stream over parent and desilicated zeolites

These findings clearly demonstrate the influence of desilication process on the catalytic performance of hierarchical zeolites. It can be expected that the cracking of large and bulky molecules over hierarchical zeolites will proceed more effectively than over their microporous counterparts. On the other hand, for reactions requiring the presence of strong acid centers a drop in activity is expected.

\subsection{Catalytic performance in LDPE and HDPE cracking processes}

Catalytic degradation of PEs over zeolites at first stage reacts with the active sites on the external surface of the zeolite grains, as its kinetic diameter is significantly larger than the pore entrance in the zeolite structure. After the preliminary reactions on the outer surface, the partly degraded products which are able to diffuse into the micropores of the zeolite are subsequently cracked at the pore entrance; then they further react on the acid sites located inside the micropores. Thus, the properties of acid sites accessible from the external surface and those situated inside micropores are both relevant, and together with the pore structure of the zeolite influence the cracking reaction activity and selectivity ${ }^{41,42}$.

The results of LDPE catalytic cracking over the parent and hierarchical ZSM- 5 zeolites as a function of temperature are presented in Figure 10. It can be noticed that the conversion curves for all the hierarchical zeolites are shifted to lower temperatures with respect to microporous parent zeolite. For the LDPE cracking, the complete conversion for all the studied zeolites, parent and modified, is obtained at temperatures lower than $400{ }^{\circ} \mathrm{C}$. The highest activity is found for samples treated with $\mathrm{NaOH} \& \mathrm{TBAOH}$ demonstrating lower values of $\mathrm{T}_{5 \%}$ and $\mathrm{T}_{50 \%}$ i.e. temperatures necessary for $5 \%$ and $50 \%$ of LDPE conversion. These results are in agreement with the acidic and textural properties, which demonstrated a high acid strength and enhanced mesoporosity after the modification with $\mathrm{NaOH} \& \mathrm{TBAOH}$.

The cracking of HDPE over the studied ZSM-5 zeolites (Figure 11) required higher temperatures than for LDPE, what can be associated with the linear character of the HDPE structure. The absence of branching which are precursors of tertiary carbocations negatively affects its susceptibility to cracking reactions ${ }^{18}$. The highest activity in the HDPE cracking is observed again for samples treated with $\mathrm{NaOH} \& \mathrm{TBAOH}$. The temperatures for $5 \%$ and $50 \%$ conversion are about $53{ }^{\circ} \mathrm{C}$ and $19{ }^{\circ} \mathrm{C}$ lower, respectively, than for the parent material. It is worth mentioning that the sample treated with $\mathrm{NaOH}$ 
$\left(5 \mathrm{~h}, 80^{\circ} \mathrm{C}\right.$ ) presents a distinctly lower activity than the other zeolites, either parent or modified ones. This lowered activity can find the explanation both in the textural and the acidic parameters. After the modification with $\mathrm{NaOH}$ for a prolonged time and at high temperature $\left(5 \mathrm{~h}, 80^{\circ} \mathrm{C}\right)$ the drop of the acid strength, and restricted pores can entail the activity reduction (Table 1 and 2). On the other hand, the materials treated with $\mathrm{NaOH} \& \mathrm{TBAOH}$ are characterized by a higher strength of the acid sites and highly developed mesopores surface with narrower pore size distribution, in comparison to those treated with $\mathrm{NaOH}$ only. It is necessary to underline that the desilication with $\mathrm{NaOH} \& \mathrm{TBAOH}$ mixture caused significantly enough changes in acidity (strength and density of accessible sites for Pn and Coll) and porosity to prompt the activity in the LDPE and HDPE cracking reactions. Thus the superior performance of the $\mathrm{NaOH} \& \mathrm{TBAOH}$-modified materials over the parent and $\mathrm{NaOH}$-treated materials results from the higher population of weaker acid sites, and the development of the external surface area leading to the enhanced catalytic degradation rate ${ }^{43}$.
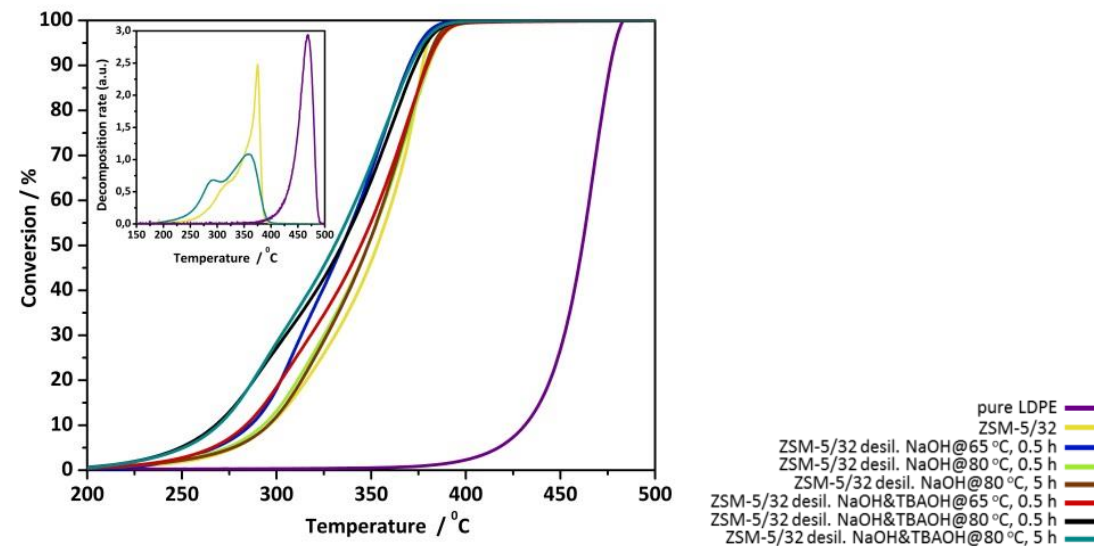

Figure 10. Results of LDPE catalytic cracking conversion as a function of temperature over the parent and desilicated ZSM-5 zeolites; decomposition rate of LDPE over selected samples (inset)
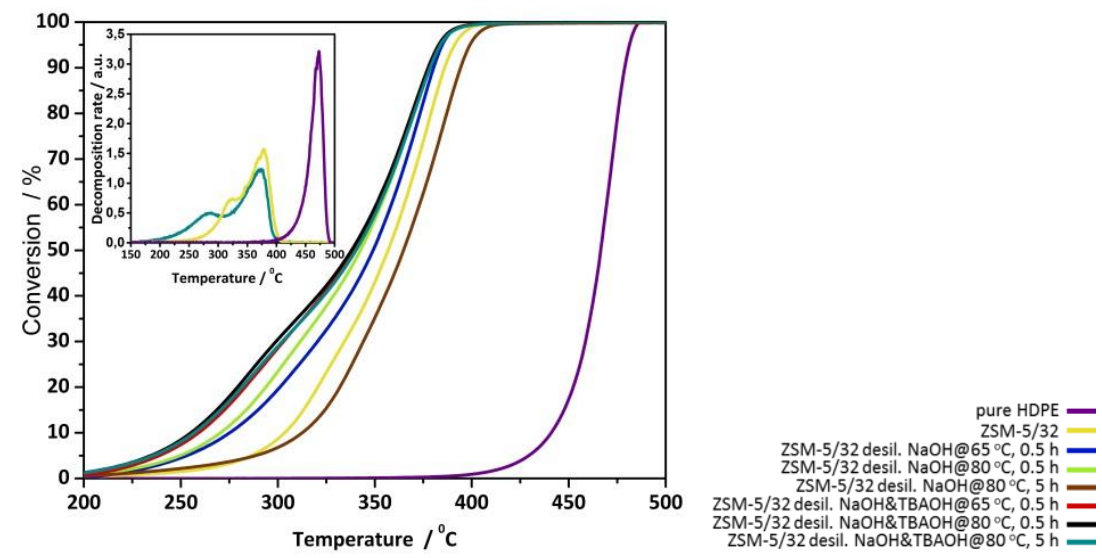

Figure 11. Results of HDPE catalytic cracking conversion as a function of temperature over the parent and desilicated ZSM-5 zeolites; decomposition rate of HDPE over selected samples (inset)

It is known that the early stage of PE cracking reaction begins with hydride abstraction or addition of a proton to $\mathrm{C}-\mathrm{C}$ bond, thus the zeolite of a higher acid strength accessible through mesopores produce more active alkylcarbenium or alkylcarbonium ions at the early stage of the reaction ${ }^{44}$. At higher temperature and conversion PEs undergo substantial cracking, and the diffusion of smaller counterparts is improved. This "leveling effect" becomes predominant over the acid strength at temperatures as high as $350^{\circ} \mathrm{C}$, where all zeolites demonstrated a more similar activity. 
When observing the conversion curves (Figs. 10 and 11), for the LDPE there are some differences between the catalysts and these may be related to meso/macroporosity differences of the external surface. The major differences are however noticed with the linear HPDE and low conversion, while at higher conversion the differences vanish. This can be quantified and evaluated. The influence of site accessibility on the catalytic activity is elegantly seen as a dependence between the estimated values of $\mathrm{AF}_{\mathrm{Pn}}$ or $\mathrm{AF}_{\mathrm{Coll}}$ and the temperatures for $5 \%$ and $50 \%$ conversion ( $\mathrm{T}_{5 \%}$ and $\mathrm{T}_{50 \%}$, resp.) (Figure 12 and 13). Linear correlations are found for both LDPE and HDPE with Pn and Coll. The increasing accessibility of the acid sites leads to an enhanced cracking activity, as observed by a decrease of the $T_{5 \%}$ and $T_{50 \%}$. It is found that the accessibility of the acid sites has a privileged influence on activity at lower temperatures. The differences in the slope of linear dependence between temperatures for both $5 \%$ and $50 \%$ conversion, and the accessibility of the acid sites, are observed depending on type of cracked polyethylene. Cracking reactions of HDPE performed over the hierarchical zeolite seem to be more influenced by the accessibility factors (i.e. more improved by the presence of mesopores) than it is seen in the case of LDPE cracking. Or in other words the LDPE is less influenced by the accessibility. This can be related to the various degree of branching of HDPE and LDPE. Since the HDPE possess a linear character, it can penetrate easily and make use of the available mesoporosity for the early-stage cracking (reflected in the $\mathrm{T}_{5 \%}$ ); therefore it is more affected by the enhanced amount of pore mouths of ZSM- 5 channels on the mesopores. High degree of branching, i.e. large amount of short hydrocarbon chains, typical for LDPE induces a more constrained access to the pore entrances. Thus the generation of the secondary mesoporosity in the studied zeolites does not influence the conversion of LDPE as significantly as it was observed for HDPE. The influence of the $T_{50 \%}$ with the accessibility factors for HDPE and LDPE is weaker than for $\mathrm{T}_{5 \%}$; this suggests that the cracking at this conversion involves intermediate molecules of smaller size with less diffusional limitations.

A final remark is devoted to the possible presence of an Al-rich shell ${ }^{30}$ in the outer surface; that would restrict the diffusion of LDPE, while the HPDE can penetrate and the internal mesoporosity is benefited. Thus, the possible presence of restricted porosity does not change the argumentation with the observed trends for $\mathrm{T}_{5 \%}$ and $\mathrm{T}_{50 \%}$.

(a) LDPE: $\mathrm{T}_{5 \%} \& \mathrm{~T}_{50 \%} /{ }^{\circ} \mathrm{C}$ vs $\mathrm{AF}_{\mathrm{Pn}_{n}}{ }^{\mathrm{B}}$

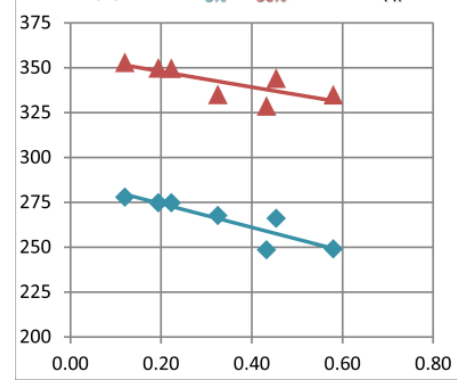

(b) HDPE: $\mathrm{T}_{5 \%} \& \mathrm{~T}_{50 \%} /{ }^{\circ} \mathrm{C} \mathrm{CS} \mathrm{AF}_{\mathrm{Pn}^{\mathrm{B}}}{ }^{\mathrm{B}}$

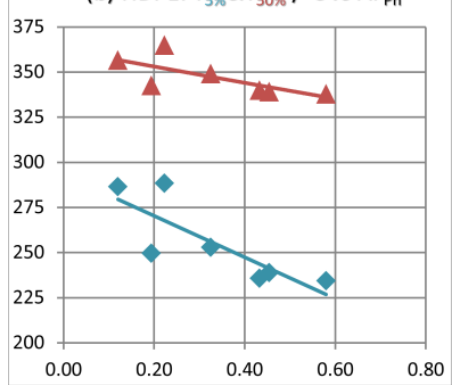

Figure 12. Temperatures for $5 \%$ and $50 \%$ conversion ( $T_{5 \%} \Delta$ and $T_{50 \%} \diamond$ ) for (a) LDPE and (b) HDPE cracking plotted against the accessibility factor values for the Brønsted acid sites estimated from pivalonitrile $\left(A F_{P_{n}}{ }^{B}\right)$ sorption experiments 
(a) LDPE: $\mathrm{T}_{5 \%} \& \mathrm{~T}_{50 \%} /{ }^{\circ} \mathrm{C}$ vs $\mathrm{AF}_{\mathrm{Coll}}{ }^{\mathrm{B}}$

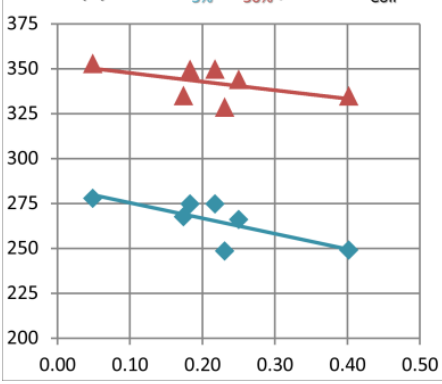

(b) HDPE: $T_{5 \%} \& T_{50 \%} /{ }^{\circ} \mathrm{C}$ vs $A F_{C_{0 l l}}{ }^{B}$

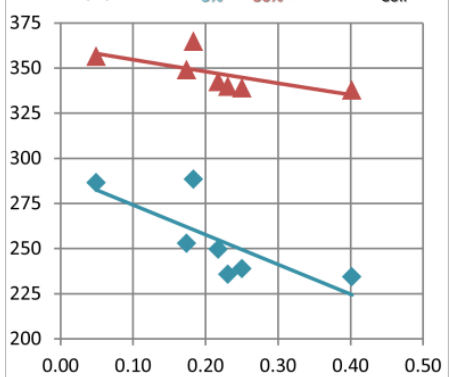

Figure 13. Temperatures for $5 \%$ and $50 \%$ conversion ( $T_{5 \%} \Delta$ and $T_{50 \%} \Delta$ ) for (a) LDPE and (b) HDPE cracking plotted against the accessibility factor values for the Brønsted acid sites estimated from collidine $\left(A F_{c o l l}{ }^{B}\right)$ sorption experiments.

\section{Conclusions}

The effectiveness of hierarchical zeolites in acid catalyzed cracking of TIPB, $n$-decane and polyethylenes was evaluated in the terms of their accessible acidity and generated mesoporosity. It has been found that the cracking of large and bulky molecules (TIPB vs $n$-decane) over the hierarchical zeolites proceeded more effectively than over their microporous counterparts, and this was correlated to the pivalonitrile and collidine accessibility factors. A similar behavior was observed for the cracking of LDPE and HDPE. Linear correlations of the temperatures for $5 \%$ and $50 \%$ conversion for LDPE and HDPE with the accessibility factors for branched probe molecules (pivalonitrile and collidine) were found. At low conversion, lineal HDPE is more sensitive by the enhanced mesoporosity, as determined by the steeper $T_{5 \%}$ correlation, than branched LDPE. At high conversion the influence of the $T_{50 \%}$ with the accessibility factors for HDPE and LDPE is weaker, suggesting that the cracking at this stage involves intermediate molecules of smaller size with less diffusional limitations.

\section{Acknowledgements}

The work was co-financed by Grant No. 2014/13/D/ST5/02761 from the National Science Centre, Poland. I. M-C thanks De Nederlandse Organisatie voor Wetenschappelijk Onderzoek (NWO) for financial support, project no. 10284. J.M.-T. thanks financial support from the Spanish Ministry of Economy and Competitiveness through the Severo Ochoa program (SEV-2012-0267) and the grant CTQ2015-68951-C3-1-R. M.J. Ortiz Iniesta is acknowledged for technical support in the TGA measurements. J. Datka is acknowledged for preliminary discussion on results presented in paper. 


\section{References}

(1) Verboekend, D.; Perez-Ramirez, J. Catalysis Science \& Technology 2011, 1 (6), 879.

(2) Gora-Marek, K.; Tarach, K.; Tekla, J.; Olejniczak, Z.; Kustrowski, P.; Liu, L.; Martinez-Triguero, J.; Rey, F. Journal of Physical Chemistry C 2014, 118 (48), 28043.

(3) Holm, M. S.; Taarning, E.; Egeblad, K.; Christensen, C. H. Catalysis Today 2011, 168 (1), 3.

(4) Liu, Y.; Zhang, W.; Pinnavaia, T. J. Steam-Stable MSU-S Angewandte Chemie International Edition 2001, 40 (7), 1255.

(5) Schmidt, I.; Boisen, A.; Gustavsson, E.; Ståhl, K.; Pehrson, S.; Dahl, S.; Carlsson, A.; Jacobsen, C. J. H. Chemistry of Materials 2001, 13 (12), 4416.

(6) Choi, M.; Cho, H. S.; Srivastava, R.; Venkatesan, C.; Choi, D.-H.; Ryoo, R. Nat Mater 2006, 5 (9), 718.

(7) Wang, H.; Pinnavaia, T. J. Angewandte Chemie International Edition 2006, 45 (45), 7603.

(8) Verboekend, D.; Milina, M.; Mitchell, S.; Pérez-Ramírez, J. Crystal Growth \& Design 2013, 13 (11), 5025 .

(9) Sadowska, K.; Gora-Marek, K.; Drozdek, M.; Kustrowski, P.; Datka, J.; Martinez Triguero, J.; Rey, F. Microporous and Mesoporous Materials 2013, 168, 195.

(10) Abelló, S.; Bonilla, A.; Pérez-Ramírez, J. Applied Catalysis A: General 2009, 364 (1-2), 191.

(11) Müller, M.; Harvey, G.; Prins, R. Microporous and Mesoporous Materials 2000, 34 (2), 135.

(12) Sadowska, K.; Gora-Marek, K.; Datka, J. Vibrational Spectroscopy 2012, 63, 418.

(13) Pérez-Ramírez, J.; Verboekend, D.; Bonilla, A.; Abelló, S. Advanced Functional Materials 2009, $19(24), 3972$.

(14) Sadowska, K.; Wach, A.; Olejniczak, Z.; Kustrowski, P.; Datka, J. Microporous and Mesoporous Materials 2013, 167, 82.

(15) Serrano, D. P.; Aguado, J.; Escola, J. M. ACS Catalysis 2012, 2 (9), 1924.

(16) Bonilla, A.; Baudouin, D.; Pérez-Ramírez, J. Journal of Catalysis 2009, 265 (2), 170. 
(17) Serrano, D. P.; Aguado, J.; Escola, J. M.; Rodriguez, J. M.; Peral, A. Journal of Catalysis 2010, $276(1), 152$.

(18) Aguado, J.; Sotelo, J. L.; Serrano, D. P.; Calles, J. A.; Escola, J. M. Energy \& Fuels 1997, 11 (6), 1225.

(19) Kumar, S.; Panda, A. K.; Singh, R. K. Resources, Conservation and Recycling 2011, 55 (11), 893.

(20) Mordi, R. C.; Fields, R.; Dwyer, J. Journal of Analytical and Applied Pyrolysis 1994, 29 (1), 45.

(21) Castaño, P.; Elordi, G.; Olazar, M.; Aguayo, A. T.; Pawelec, B.; Bilbao, J. Applied Catalysis B: Environmental 2011, 104 (1-2), 91.

(22) Elordi, G.; Olazar, M.; Lopez, G.; Castaño, P.; Bilbao, J. Applied Catalysis B: Environmental 2011, $102(1-2), 224$.

(23) Barrett, E. P.; Joyner, L. G.; Halenda, P. P. Journal of the American Chemical Society 1951, 73 (1), 373.

(24) Góra-Marek, K.; Derewiński, M.; Sarv, P.; Datka, J. Catalysis Today 2005, 101 (2), 131.

(25) Sadowska, K.; Gora-Marek, K.; Datka, J. Journal of Physical Chemistry C 2013, 117 (18), 9237.

(26) Mlekodaj, K.; Tarach, K.; Datka, J.; Gora-Marek, K.; Makowski, W. Microporous and Mesoporous Materials 2014, 183, 54.

(27) Corma, A.; Martínez-Triguero, J. Applied Catalysis A: General 1994, 118 (2), 153.

(28) Groen, J. C.; Peffer, L. A. A.; Moulijn, J. A.; Pérez-Ramírez, J. Chemistry - A European Journal 2005, $11(17), 4983$.

(29) Majda, D.; Tarach, K.; Góra-Marek, K.; Michalik-Zym, A.; Napruszewska, B. D.; Zimowska, M.; Serwicka, E. M. Microporous and Mesoporous Materials 2016, 226, 25.

(30) Groen, J. C.; Bach, T.; Ziese, U.; Paulaime-van Donk, A. M.; de Jong, K. P.; Moulijn, J. A.; PérezRamírez, J. Journal of the American Chemical Society 2005, 127 (31), 10792.

(31) Thibault-Starzyk, F.; Stan, I.; Abelló, S.; Bonilla, A.; Thomas, K.; Fernandez, C.; Gilson, J.-P.; Pérez-Ramírez, J. Journal of Catalysis 2009, 264 (1), 11. 
(32) Tarach, K.; Gora-Marek, K.; Tekla, J.; Brylewska, K.; Datka, J.; Mlekodaj, K.; Makowski, W.; Igualada Lopez, M. C.; Martinez Triguero, J.; Rey, F. Journal of Catalysis 2014, 312, 46.

(33) Lee, J. Y.; Park, S. M.; Saha, S. K.; Cho, S. J.; Seo, G. Applied Catalysis B: Environmental 2011, $108-109,61$.

(34) Milina, M.; Mitchell, S.; Crivelli, P.; Cooke, D.; Pérez-Ramírez, J. Nat Commun 2014.

(35) Tarach, K. A.; Martinez-Triguero, J.; Rey, F.; Góra-Marek, K. Journal of Catalysis 2016, 339, 256.

(36) Corma, A.; Miguel, P. J.; Orchille's, A. V. Applied Catalysis A: General 1994, 117 (1), 29.

(37) Xu, B.; Sievers, C.; Hong, S. B.; Prins, R.; van Bokhoven, J. A. Journal of Catalysis 2006, 244 (2), 163.

(38) Corma, A.; Melo, F.; Sauvanaud, L.; Ortega, F. J. Applied Catalysis A: General 2004, 265 (2), 195.

(39) Karge, H. G.; eds. van Bekkum, H.; Flanigen, E.M.; Jacobs, P.A.; J.C. Jansen, J.C.; Studies in Surface Science and Catalysis; Elsevier, 2001, 137, 707.

(40) Weitkamp, J.; Hunger, M.; eds. Čejka, J.; van Bekkum, H.; Corma, A.; Schüth, F.; Studies in Surface Science and Catalysis; Elsevier, 2007, 168, 787.

(41) You, Y. S.; Kim, J.-H.; Seo, G. Polymer Degradation and Stability 2001, 72 (2), 329.

(42) Manos, G.; Garforth, A.; Dwyer, J. Industrial \& Engineering Chemistry Research 2000, 39 (5), 1198.

(43) Zhou, Q.; Wang, Y.-Z.; Tang, C.; Zhang, Y.-H. Polymer Degradation and Stability 2003, 80 (1), 23.

(44) Zhang, H.; Ma, Y.; Song, K.; Zhang, Y.; Tang, Y. Journal of Catalysis 2013, 302, 115. 